Session No:391 T233. Tectonics,

Geohazards, and Morphodynamics and Imagery (Posters) HSA 2017 from High-Resolution Topography
PNIMER CLAUSTRO UNIVERSITARIO DE COLOMBIA

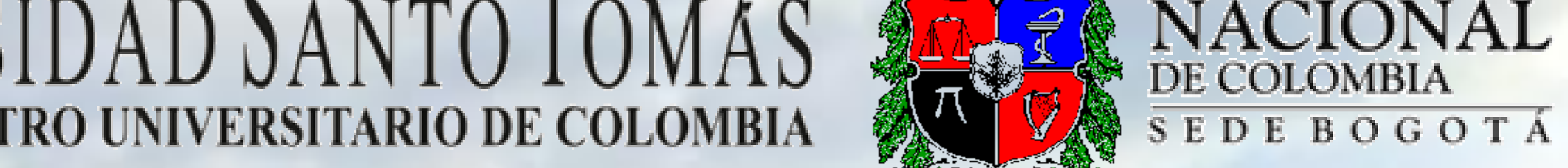
DE COLOMBIA
SED B O O O TA
FACULAD DE CIENCLAS

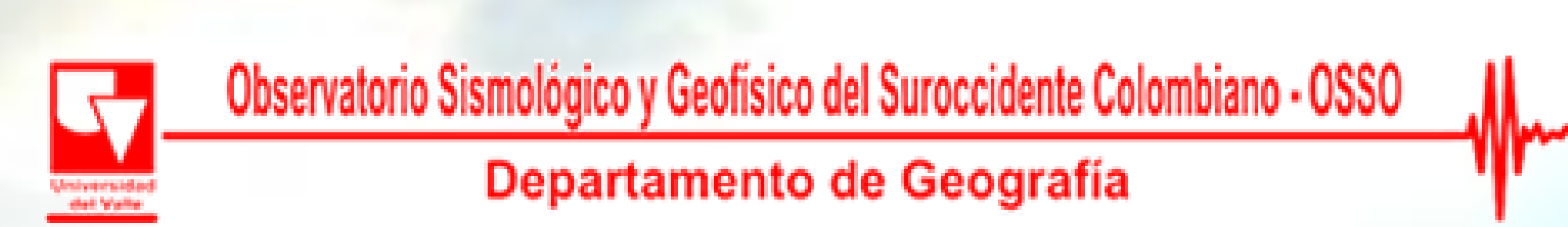

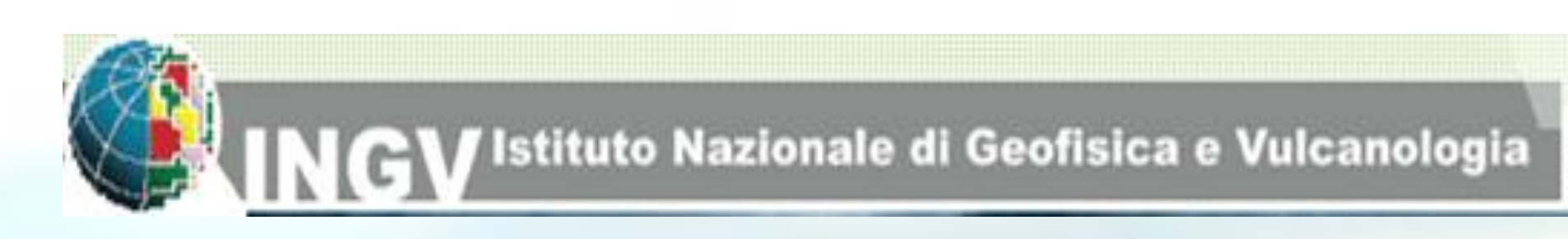
22-25 October

\title{
GEOTECTONIC EVOLUTION AND SEISMOTECTONICS OF NORTH FAULTS OF ALGECIRAS FAULT SYSTEM, COLOMBIA
}

\section{Chicangana, G. ${ }^{1}$, Bocanegra, G, A. ${ }^{1}$, Kammer, A. ${ }^{2}$, Vargas, C. ${ }^{2}$, Salcedo, H, E. ${ }^{3}$, Gómez - Capera, A. ${ }^{4}$}

1. Universidad Santo Tomás, Colombia. 4. Universi uad Nacional de Colombia. 3.Universidad del Valle, Colombia. 4..Istituto Nazionale di Geofísica e Vulcanologia, Italy. ABSTRACT

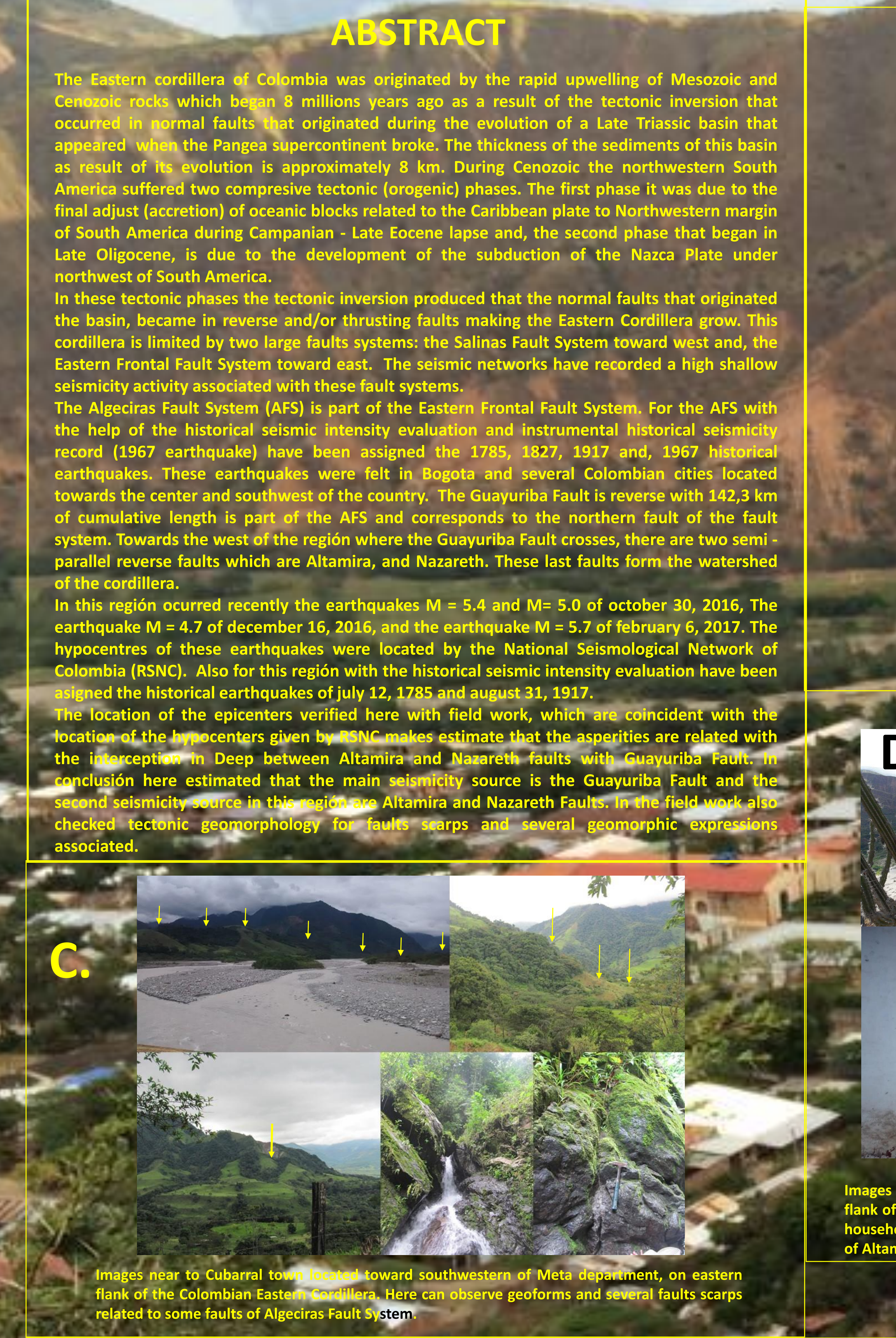

F.

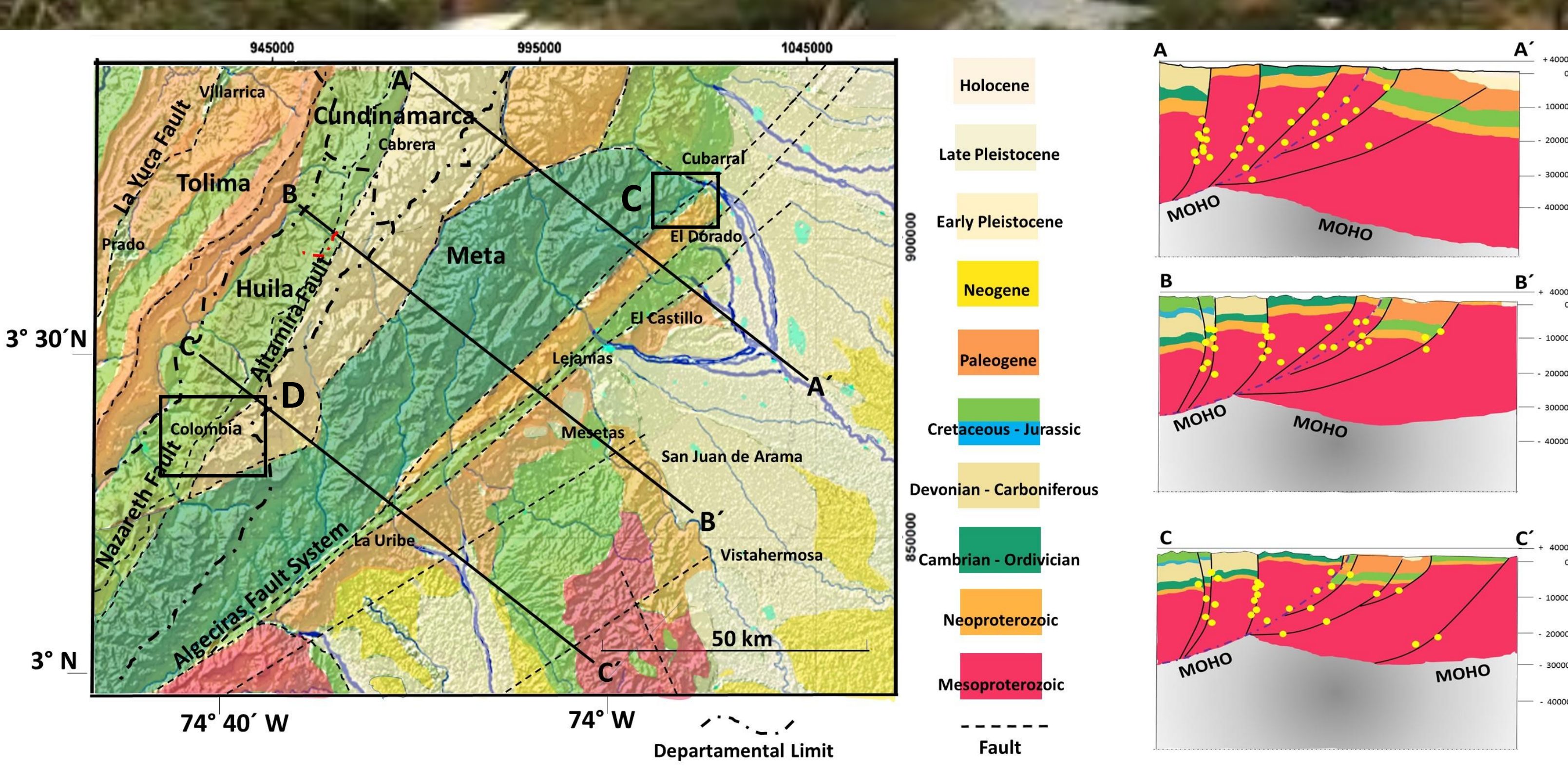

A. LOCATION



\section{D.}
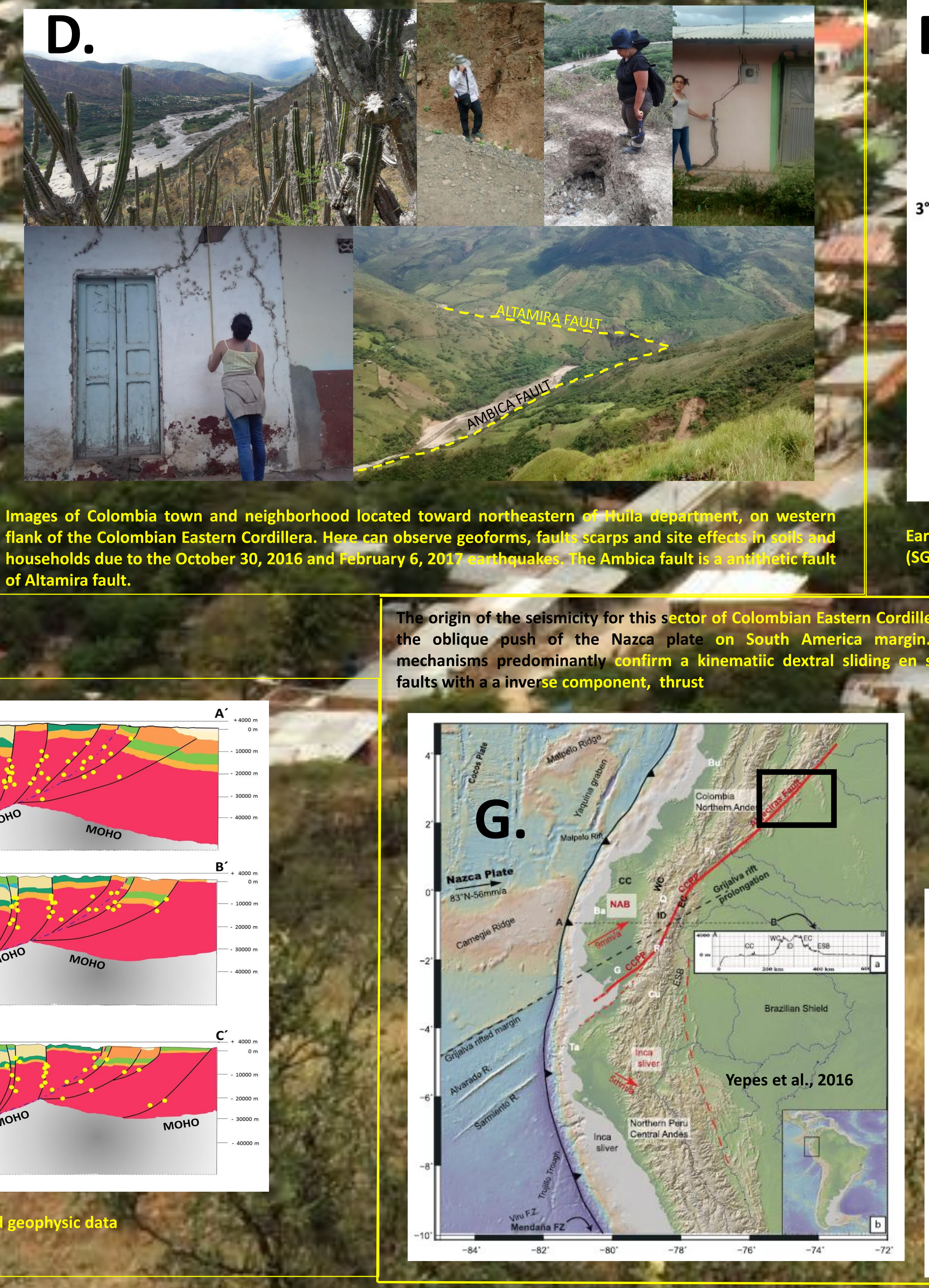

B. HISTORICAL SEISMICITY

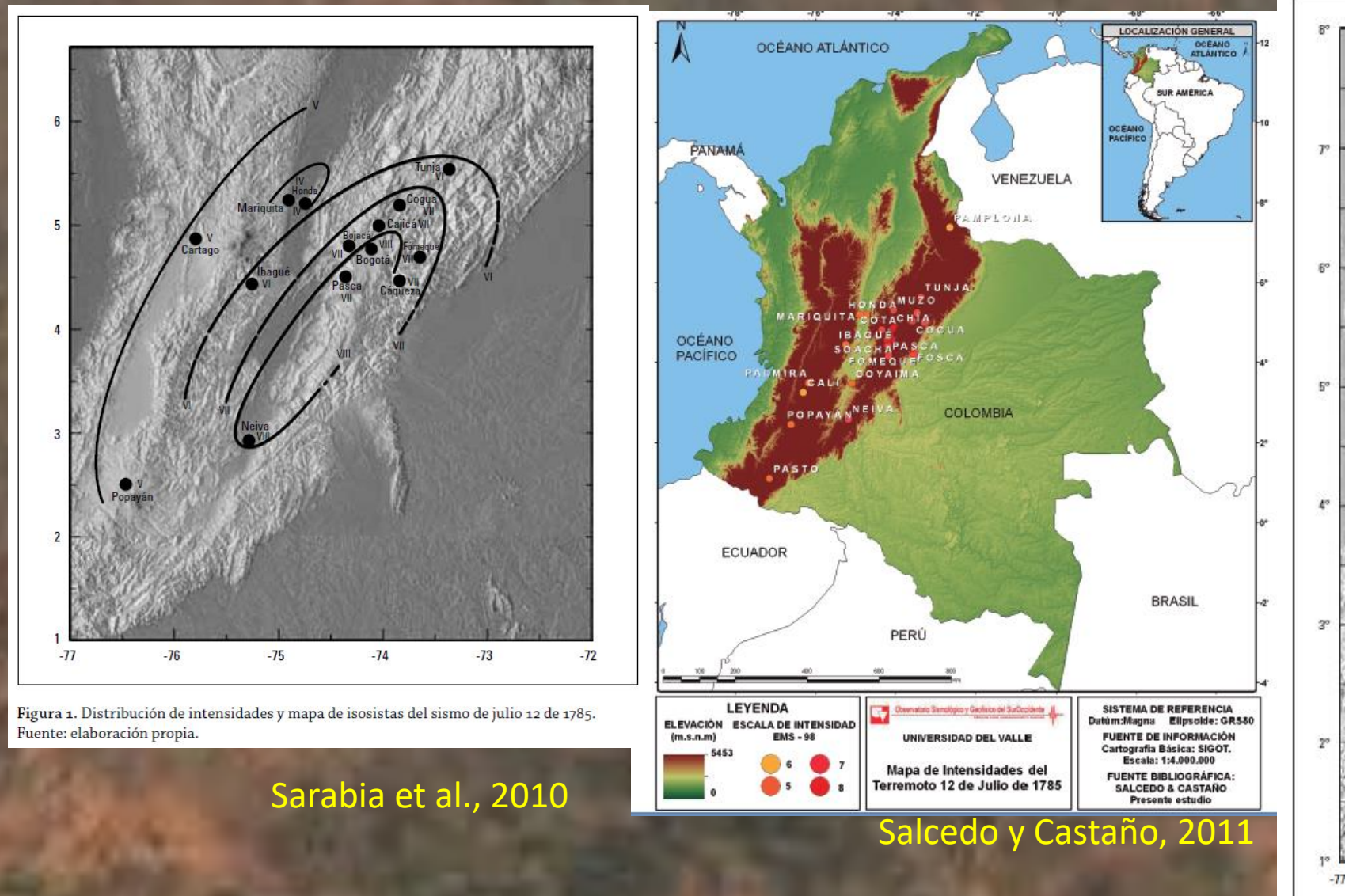

JULY 12, 1785 EARTHQUAKE
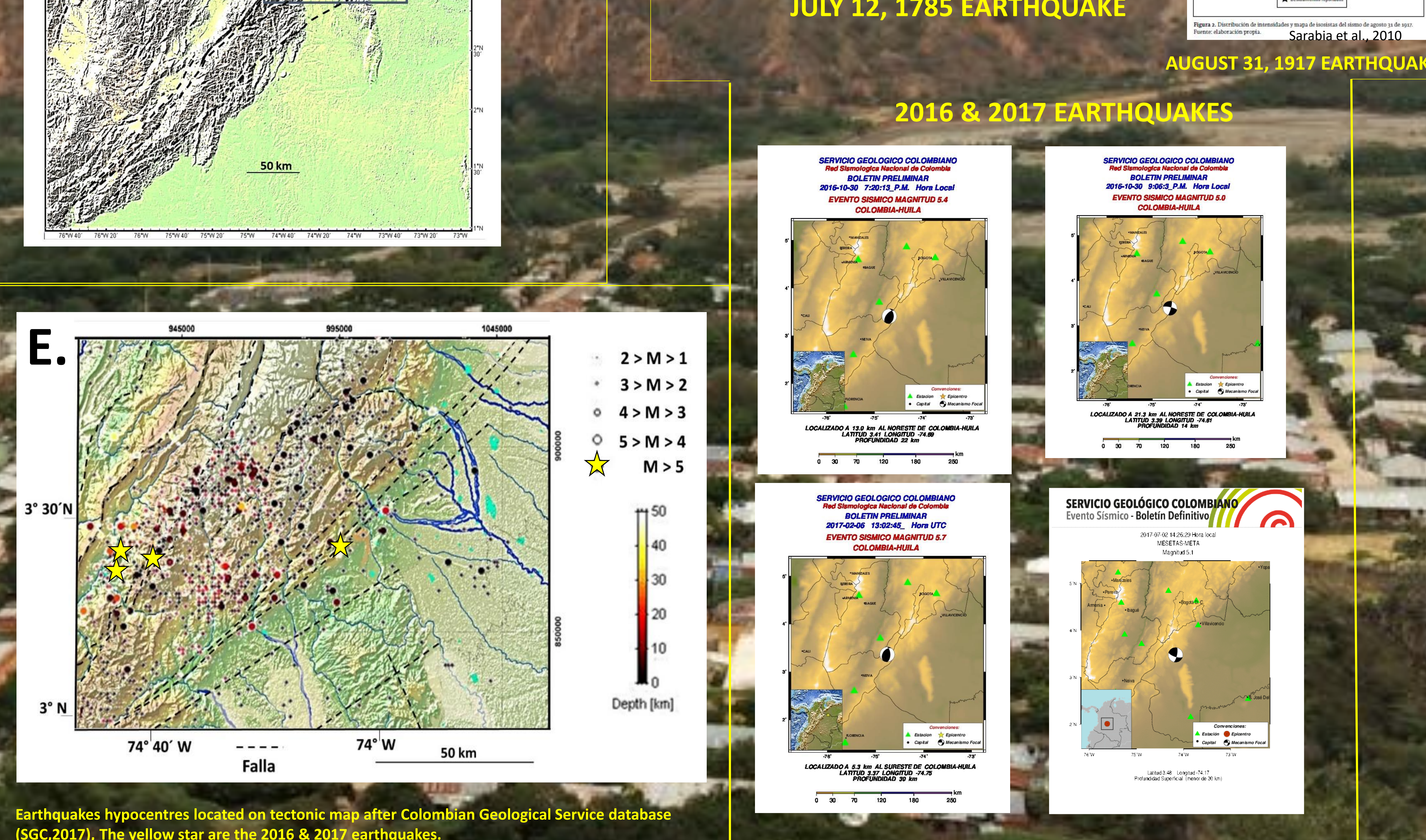
8 T2016 \& 2017 EARTHQUAKES
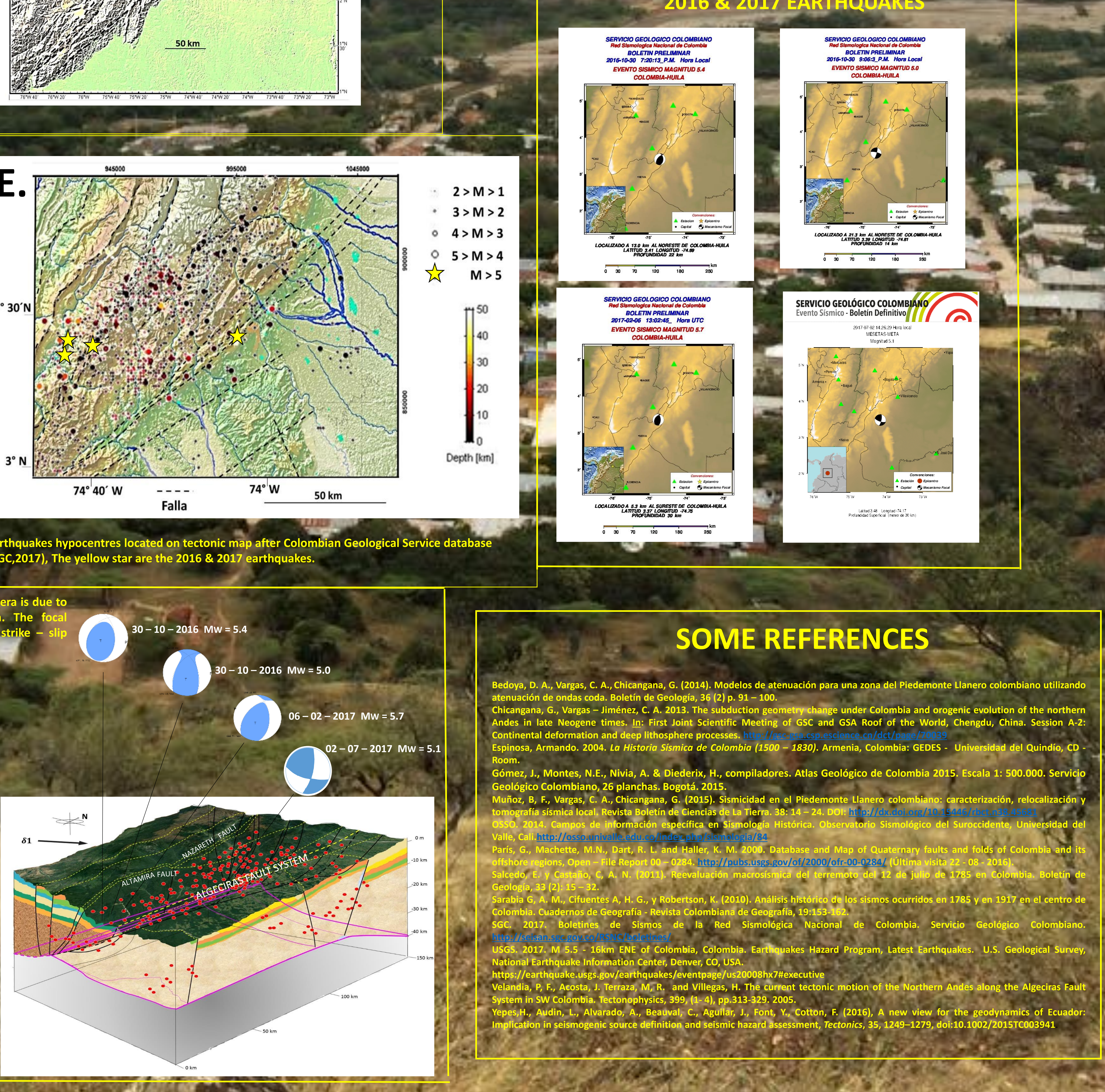